\title{
Anorectal anomaly with rectovestibular fistula: a historical comparison of neonatal anterior sagittal anorectoplasty without covering colostomy and postoperative anal dilatation to the classical three-stage posterior sagittal anorectoplasty
}

This article was published in the following Dove Press journal:

Open Access Surgery

16 August 2017

Number of times this article has been viewed

\author{
Dayang Anita Abdul Aziz' \\ Ramamoorthy Velayutham ${ }^{2}$ \\ Marjmin Osman' \\ Zarina Abdul Latiff ${ }^{3}$ \\ Felicia SK Lim ${ }^{4}$ \\ Mahmud Mohd Nor' \\ 'Department of Surgery, UKM \\ Medical Centre, Kuala Lumpur, \\ ${ }^{2}$ Department of Surgery, Hospital Raja \\ Permaisuri Bainun, Ipoh, ${ }^{3}$ Department \\ of Paediatrics, ${ }^{4}$ Department of \\ Anaesthesia, UKM Medical Centre, \\ Kuala Lumpur, Malaysia
}

Correspondence: Dayang Anita Abdul Aziz

Department of Surgery, UKM Medical Centre, Bandar Tun Razak, 56000

Cheras, Kuala Lumpur, Malaysia

Fax +60391456684

Email dayanganita@gmail.com
Background: Traditional three-stage posterior sagittal anorectoplasty (PSARP) is a widely used operational technique for rectovestibular fistula (RVF) which includes creation of stoma, definitive surgery, and subsequent closure of stoma. Three-stage PSARP is usually completed during infancy. Many pediatric surgeons across the world have embarked on anterior sagittal anorectoplasty (ASARP) as an alternative technique to reduce pelvic floor dissection and the need to operate with patients in the prone position. ASARP is performed with the patient lying in supine position and it can be performed as one-stage repair during the neonatal period. Early reports from many centers are showing promising results. An outcome comparison of both techniques is vital to help surgeons consider this new approach in the repair of RVF.

Patients and methods: This is a retrospective historical comparison study. Nine neonates with RVF underwent primary ASARP without postoperative anal dilatation and were compared to 25 patients with RVF who underwent three-stage PSARP with postoperative anal dilatation. Immediate surgical outcome was reviewed from the records and follow-up sheets of individual patients and functional outcome was assessed by interviewing the parents. Results were compared statistically; $P$-value $\leq 0.05$ was considered significant.

Results: The immediate surgical complications were higher in the PSARP group (40\%) compared to the ASARP group (22\%). Functional outcome showed overall better outcome in ASARP compared to PSARP. Patients from both groups did not develop stenosis, although only the PSARP group was subjected to daily anal dilatation.

Conclusion: Primary neonatal ASARP without dilatation is a good technique for RVF in girls. Immediate complication rates were lower to those in PSARP. However, both immediate surgical and functional outcome between the ASARP and PSARP groups did not show overall statistical significance in this study. However, the ASARP technique has improved the ease of overall care of children with this condition.

Keywords: neonate, anorectal anomaly, ASARP, PSARP

\section{Definitions}

\section{Anterior sagittal anorectoplasty (ASARP)}

Devised by Okada et $\mathrm{al}^{1}$ for repair of rectovestibular or anovestibular fistula, the patient is operated on in a lithotomy position; a median perineal skin incision is made and the sphincter muscles are cut from it. Rectum is then brought out through the external sphincter muscles centrally. 


\section{Rectovestibular fistula (RVF)}

The rectum terminates at or just below the pubococcygeal line, with an anterior fine fistula, $1-2 \mathrm{~cm}$ along the vestibule, coursing immediately adjacent to the posterior wall of the vagina. The terminal gut is supralevator, the fistula translevator. The vagina is often double. Diagnosis is made based on the following features:

1. Three orifices in vestibule, urethra, vagina, and a fine rectal fistula in fossa navicularis. Orifice totally surrounded by red vestibular mucosa. ${ }^{1,2}$

2. Probe into fistula passed cranially only. ${ }^{1}$

\section{Posterior sagittal anorectoplasty (PSARP)} PSARP is the most commonly used operation for the repair of anorectal anomaly (ARA). ${ }^{3-6}$ In this procedure, the patient is positioned prone. The contraction of the anal complex is predetermined by electrostimulation prior to making a midline incision. The layers of muscles are split in layers with careful preservation before delivering the rectum down, as exactly described by de Vries and Pena. ${ }^{5}$

\section{Introduction}

ARA in girls encompasses a spectrum of defects ranging from imperforate anal membrane to persistence of an undifferentiated cloaca. Rectovestibular or anovestibular fistula is the commonest ARA in female patients. ${ }^{2,7}$ In this condition, the anal opening (vestibule) lies between the vagina and the fourchette.

The incidence of ARA is reported to be 2.0-2.5 per 10,000 live births. ${ }^{8}$ There are variations in the prevalence between geographical areas in the world. Louw reported an incidence of 5.5 per 10,000 live births in South Africa. ${ }^{9}$ In British Columbia, the incidence was 4.0 per 10,000 live births. ${ }^{10}$ In India, various studies have revealed a high prevalence, with ARA; some units have as high as $15 \%$ of admission as a result of ARA; however, overall incidence figures are not presently available. ${ }^{11,12}$ In the far east, the prevalence is reported to be between 3.38 and 5.04 per 10,000 births for South Korea, Japan, and China. ${ }^{13,14}$ Closer to home, the incidence in Singapore is about 0.86 per 10,000 births..$^{15}$ In Malaysia, there are no published local data available on the incidence of ARA. In a busy tertiary center like Hospital Kuala Lumpur, from an internal audit done in 2007 , there are about 10 ARAs a year - with one third being RVF.

Historically, there are several operative techniques described for the treatment of RVF patients that is, anal cutback, ${ }^{7}$ perineal anal transplant, ${ }^{1} \mathrm{Y}-\mathrm{V}$ and X-Z-plasty, ${ }^{16}$ colostomy followed by limited PSARP, ${ }^{4}$ and sacroperineal repair. ${ }^{17}$ However, results have not always been satisfactory for these procedures, both functionally and cosmetically. The poor outcome is attributed to various issues related to failure of recognizing the correct anatomy, issues with bringing down the rectum, poor appearance of the perineum, with the longterm result of anterior migration of the anus. ${ }^{18}$

Since de Vries and Pena introduced PSARP, ${ }^{5}$ the technique has become the main surgical technique for RVF because the postoperative outcome had improved significantly at functional and clinical levels. ${ }^{419-21}$ Traditional PSARP is a three-stage repair technique which includes formation of a colostomy, a procedure mainly used to divert the fecal stream for decompression, and to protect the anocutaneous anastomosis after a reconstructive repair. Subsequently, most surgeons subject patients to diligent daily anal dilatation programs to avoid ano-anastomotic stricture before finally carrying out stoma closure.

However, most recently, ASARP with or without colostomy is being practiced as an alternative to three-stage PSARP repair in some centers and the published results look promising. ${ }^{18,22,23}$

PSARP and ASARP have revolutionized the surgical treatment of ARA over the last decade. ASARP is an optimal technique for intermediate ARAs and shows better cosmetic and functional outcome by reducing postoperative constipation compared to PSARP. ${ }^{24,25}$

Similar to PSARP, the incision in ASARP is oriented along the sagittal plane. However, the primary advantage of ASARP is that, only the anterior aspect of the sphincteric muscle complex is divided and continence mechanism is preserved. ${ }^{18,26}$ Moreover, as clearly alluded by Wakhlu et al "ASARP allows placement and anchoring of the mobilized rectum within the muscle complex; the sphincteric muscle and the perineal body are accurately reconstituted and a normal perineum is reconstructed". ${ }^{18}$

More pediatric surgeons have converted to repairing ARA without a covering colostomy, mainly based on the understanding of the complications associated with colostomy and evidence from the current literature. ${ }^{27-32}$ Though differences of opinion still exist, primary ASARP is a good and acceptable technique for RVF. $22,25,33-35$

Primary ASARP is easily applicable and safe in neonates. ${ }^{21,22}$ Furthermore, available evidence shows that functional results are better if the repair is done as early as possible. ${ }^{36}$ Better outcomes are seen in younger patients, shorter distance between the perineal skin and rectum, and 
lesser degree of tension in the rectoanal anastomosis. ${ }^{37}$ Early repair prevents the loss of cortical integration of somatosensory input from anal skin and enhances the development of normal stooling patterns at the appropriate time. ${ }^{38-40}$

Traditionally, postoperative neoanal dilatation is a routine practice among pediatric surgeons to avoid anocutaneous stricture and to ensure a patent anus prior to closure of colostomy. However, there is no clear evidence that it is beneficial in preventing anocutaneous anastomotic narrowing while the effects of dilatations during infancy remain to be proven.

Instead, anocutaneous anastomotic stricture is potentially caused by anastomotic complications, which include inadequate blood supply, excessive tension during suturing, technical error in suture placement, or physical injury to the anastomosis in the postoperative period..$^{41}$ Primary ASARP, done diligently, reduces tissue dissection and causes less vascular compromise, preventing this stricture. ${ }^{41}$

This study also includes the assessment of continence postprimary ASARP without postoperative anal dilatation. ASARP minimizes the damage to posterior nervi erigentes and prevents excessive damage to puborectalis and internal and external sphincters to preserve normal rectoanal reflexes. ${ }^{40,42}$

It is unclear which surgical method offers the best immediate, delayed, and long-term functional results in patients with RVF. Neonatal ASARP without colostomy and dilatation (the intervention group) is a novel technique; therefore, there has been no other research prior to this addressing the short- and long-term outcome of this procedure. Traditional PSARP on the other hand is a well-established technique and many papers have been published to describe its clinical outcome; the rate of wound infection, complications of colostomy, stricture rate, and continence.

Based on previous literature, we were able to perform a retrospective historical comparison of the common parameters of both techniques. The purpose of this historical comparison is to demonstrate the immediate, delayed, and long-term functional outcome of primary neonatal ASARP compared to that of PSARP and show evidence that it is indeed a superior surgical technique.

\section{Research objectives General objectives}

The general objective of this study is to compare the immediate, delayed, and long-term outcome of ASARP without covering colostomy and postoperative anal dilatation to the classical three-stage PSARP repair.

\section{Primary specific objectives}

1. To compare the incidence of immediate complications, that is, perineal body disruption and surgical site infection between neonatal ASARP without colostomy and classical three-stage PSARP repair for RVF.

2. To compare the incidence of neoanus stricture between primary ASARP without dilatation and classical threestage PSARP repair with regular dilatation.

3. To compare the bowel function between patients with postprimary ASARP and classical three-stage PSARP repair.

\section{Secondary specific objectives}

To objectively assess perineal body contraction, neoanus contraction, and the size and position of neoanus post-surgery in patients undergoing primary ASARP.

\section{Materials and methodology Design of study}

This is a retrospective historical comparison study. It was approved by the UKM Medical Centre (UKMMC) Medical Research and Ethics Committee (approval code: FF-2013349). The committee waived the need for parental consent for retrieval of previous records as long as patients' confidentiality was maintained. However, for interview with parents regarding assessment of bowel function of their children, all parents gave their written consent before recruitment and inclusion in this study.

We could not conduct a randomized control trial due to the reduced local incidence of RVF in many centers throughout the country during the period of study. Data were obtained from the records and follow-up sheets kept in the Medical Records Department, UKMMC.

\section{Study population}

All neonates with RVF who underwent primary neonatal ASARP and three-stage PSARP were included in this study.

1. Inclusion criteria

- All neonates with RVF who underwent primary ASARP or three-stage PSARP.

2. Exclusion criteria

- Failure to get consent from parents, for the interview session in clinic for assessment on continence.

- Neonates who did not undergo primary ASARP or three-stage PSARP.

\section{Standardizations}

Regarding neonatal ASARP, the operative technique is in accordance to the ASARP approach that utilizes the same 
basic principle as that described by Okada et al, ${ }^{1}$ Wakhlu et al, ${ }^{18}$ and Aziz et al. ${ }^{37}$ Surgery was performed by the consultant pediatric surgeon of the Pediatric Surgery Unit, UKMMC. Postoperatively, the perineal wound is irrigated with saline regularly at 6-hour intervals and neonates were allowed oral intake immediately post-surgery.

The records of immediate postoperative reports were traced and reviewed, particularly to assess the parameters mentioned in Section B of Proforma on ASARP (Supplementary materials) to evaluate contraction of the anal complex and state of the wound. Subsequently, records on examination under anesthesia (EUA) obtained at 1 month postoperatively were reviewed to look for the same specific parameters as mentioned in Section B of Proforma on ASARP (Supplementary materials).

Patients with the classic three-stage PSARP would have previously undergone multistage surgery. Initially, there would be creation of stoma during the neonatal period. Subsequently, they would undergo PSARP during infancy. The PSARP cases were handled by a senior pediatric surgeon with $>10$ years experience as a consultant pediatric surgeon. The standard operative technique for PSARP follows the same basic principles as that described by de Vries and Pena. ${ }^{5}$ Postoperatively, the parents/guardian would perform anal dilatation on a daily basis using fingers or calibrated candles to maintain patency of the neoanus. Once the neoanus reached an adequate caliber, closure of stoma would then be carried out. All the required parameters as mentioned in Section B of Proforma on PSARP (Supplementary materials) were documented after careful review of the clinical records.

Parents were given a set of questions to answer regarding their child's bowel habit and continence (Supplementary $\underline{\text { materials }) . ~ T h e s e ~ p a r e n t a l ~ q u e s t i o n n a i r e s ~ w e r e ~ r e s e a r c h e r-~}$ administered, mostly via phone calls. Data from the questionnaires for parents were entered into Section C of the Proforma (Supplementary materials; Figure 1). However, only children $>2$ years old who were considered as being toilet trained were included in the statistical analysis.

\section{Data sampling and data analysis}

The e-version of Power and Sample Size Program (Power and Sample Size Calculation version 3.1.2, 2014. Dupont WD, Plummer WD, Jr.; Vanderbilt University, Nashville, TN, USA) was used to determine the sample size. This is a study of independent cases and controls with three control(s) per case. Prior data indicated that the probability of exposure among controls is 0.6 . If the true probability of exposure among cases is 0.05 , we needed to study seven case patients and 21 control subjects to be able to reject the null hypothesis that failure rates for experimental and control subjects are equal with a probability (power) of 0.8 . The type I error probability associated with this test of null hypothesis is 0.05 . We used an uncorrected chi-squared statistic to evaluate this null hypothesis.

Data analysis was performed using the IBM Statistical Program for Social Science, version 20 (IBM Corporation, Armonk, NY, USA). Statistical analysis was performed using $2 \times 2$ or Fisher's exact test for categorical data. $P$-values $<0.05$ were considered significant. Sample size was obtained following discussion with the Head of Clinical Epidemiology Unit (CEU) of UKMMC. This study used dichotomous analysis. The design is independent, case control. The level of significance $(\alpha)$ was set at 0.05 . The power was set as $1-\beta$ with $(\beta=20)=0.8$. Standard deviation was derived by comparing the incidence of colostomy-related complications ranged at $\mathrm{P}_{\mathrm{o}}\left(60 \%\right.$; Nour et $\left.\mathrm{al}^{43}\right)$ to patients without colostomy where complications are documented as $\mathrm{P}_{1}$ (5\% of patients; Wakhlu et $\left.\mathrm{al}^{23}\right)$. As such, the insert values were as follows:
$\alpha \quad-0.05$
$\beta \quad-0.8$
$\mathrm{P}_{\mathrm{o}} \quad-0.6(60 \%)$
$\mathrm{P}_{1} \quad-0.05(5 \%)$

$\mathrm{m}$ ratio of control to experimental was 3:1 (in view of the ASARP arm, only nine documented cases have been performed to date at UKMMC).

The sample size derived from the software was then verified by the Head of CEU of UKMMC.

\section{Results and analysis \\ Age}

There were nine patients with RVF treated with neonatal ASARP at UKMMC, over a period of 4 years. These patients underwent ASARP when they were between 2 and 4 days old (Figure 2).

There were 25 patients recruited in the three-stage repair group from 1997 to 2013 . Ninety-two percent of patients were $\leq 1$ year old, with the mean age of 7 months and median age of 6 months. Most patients were operated at between the age of 3 and 7 months (64\%). The youngest patient underwent PSARP at 2 months of age and the oldest was 2 years and 3 months old (Figure 3).

\section{Weight}

Most patients had appropriate gestational age weight, that is, $77.7 \%$ ranging from 2.6 to $3.5 \mathrm{~kg}$ (Figure 4). Mean weight 


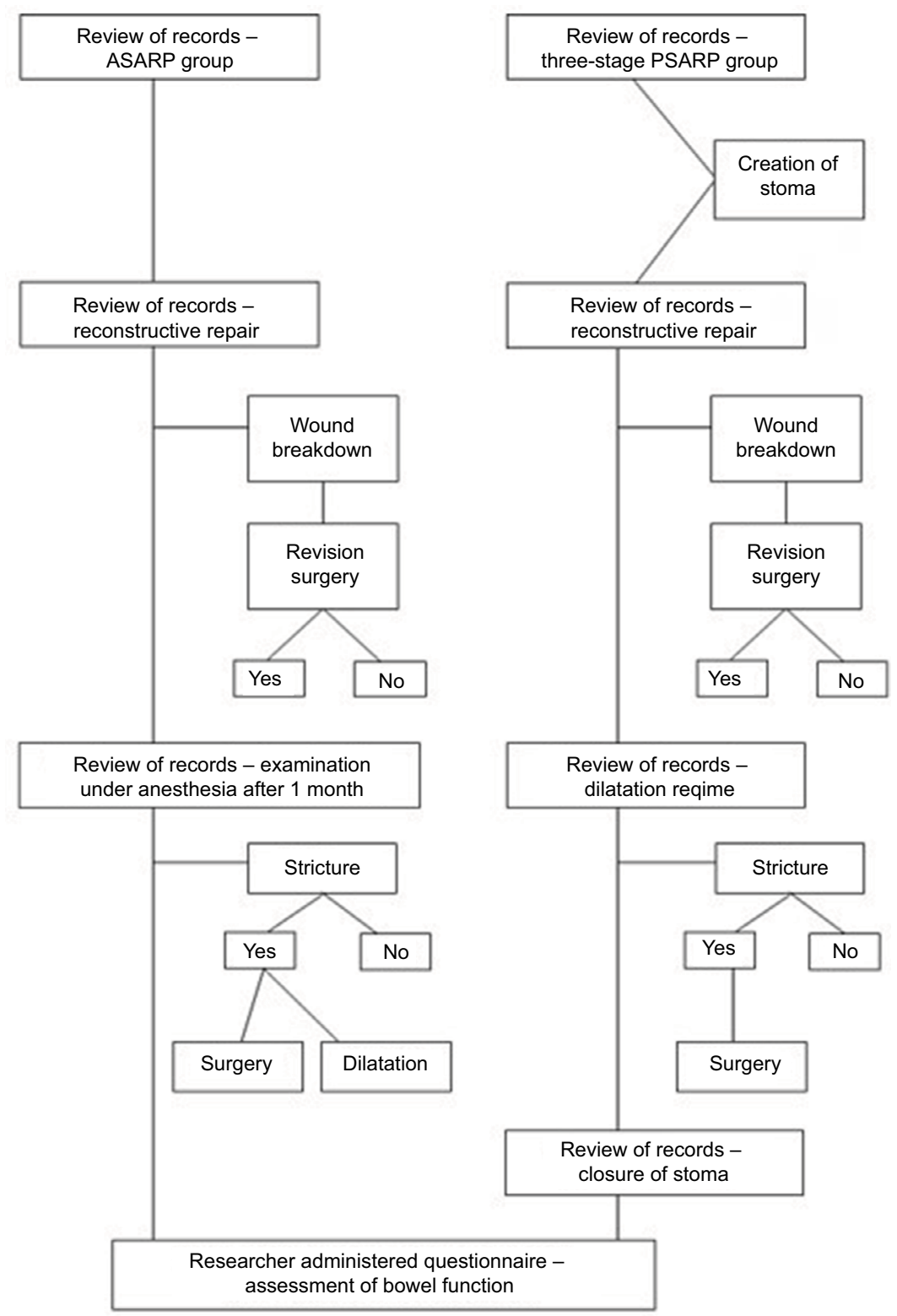

Figure I Study flow chart.

Abbreviations: ASARP, anterior sagittal anorectoplasty; PSARP, posterior sagittal anorectoplasty.

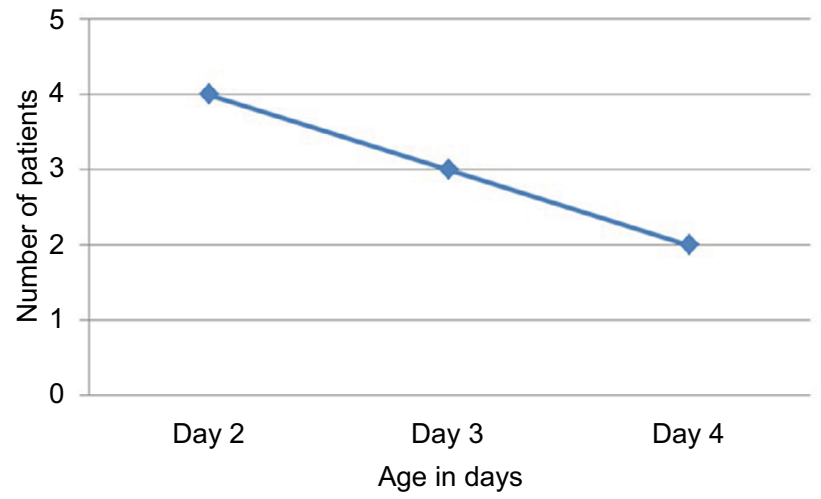

Figure 2 Age distribution of ASARP patients.

Abbreviation: ASARP, anterior sagittal anorectoplasty. as well as median weight was $3 \mathrm{~kg}$. The smallest baby was $2.5 \mathrm{~kg}$ and the heaviest baby was $3.7 \mathrm{~kg}$.

We noted that patients from the PSARP group weighed more than patients in the ASARP group at the time of surgery, that is, mean weight was $6.45 \mathrm{~kg}$ and median weight was $6.15 \mathrm{~kg}$. The lightest patient weighed $4.2 \mathrm{~kg}$ and the heaviest $11 \mathrm{~kg}$ (Figure 5).

\section{Associated anomalies}

In the ASARP group, two patients had associated anomalies; that is, both had cardiac anomalies. One had a small patent ductus arteriosus and the other had a small atrioseptal defect (Table 1). 


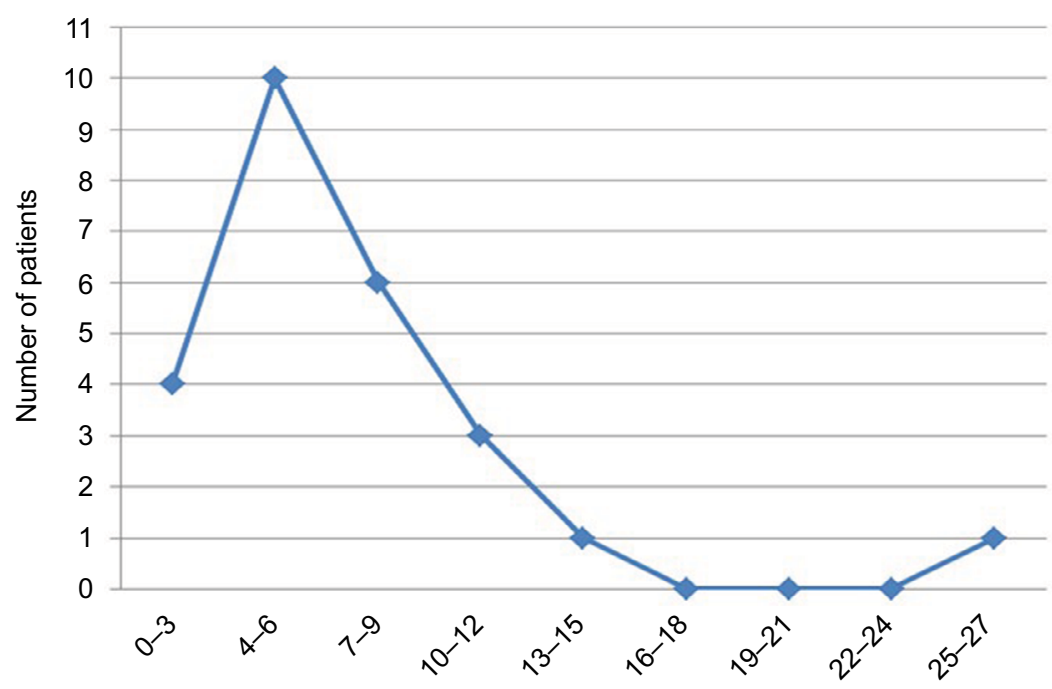

Age groups of patients in months

Figure 3 Age distribution of PSARP patients at the point of definitive surgery.

Abbreviation: PSARP, posterior sagittal anorectoplasty.

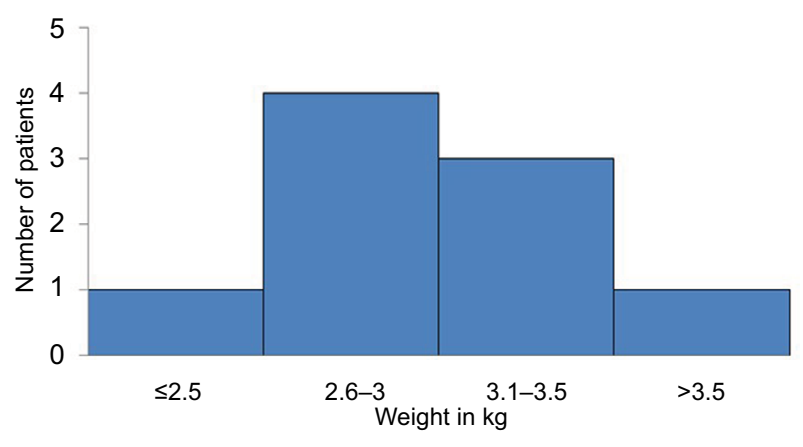

Figure 4 Weight distribution of ASARP patients. Abbreviation: ASARP, anterior sagittal anorectoplasty.

In the PSARP group, out of 25 patients, 15 had associated anomalies. Among these 15 patients, three had single organ anomaly, four patients had double organ anomalies, and three patients had multiple organ anomalies. Three patients had veterbral anorectal cardiac tracheoesophageal renal limbs (VACTERL) association while two patients had Down syndrome. Among these patients, there were seven who had a neurological anomaly associated with the brain or spine, for example, holoprosencephaly, spinal vertebrae deformities (Table 1).

\section{Findings of EUA of ASARP patients}

During the examination immediately post-surgery, whilst still under general anesthesia, all patients had good perineal



Figure 5 Weight distribution of PSARP patients.

Abbreviation: PSARP, posterior sagittal anorectoplasty.

body and neoanal contraction. The neoanus for all patients was calibrated to size 9 Hegar dilator. Immediately, during the postoperative period, the first two patients experienced wound breakdown over the perineal body (Table 2). However, there was no wound breakdown of the neoanus. Feeding was established at postoperative day 1 .

EUA at 1 month post-surgery revealed that all patients had normal looking perineal body with good contraction including the two patients with the initial perineal body breakdown. There was no recurrence of fistula in any patient. The size of neoanus in all patients was reduced to size 8 Hegar dilator but was still appropriate for age (for a 1-month old baby). All patients continued to have good contraction of the neoanus. 
Table I Associated anomalies in ASARP and PSARP patients

\begin{tabular}{|c|c|c|c|}
\hline \multirow[t]{2}{*}{ Systems } & \multirow[t]{2}{*}{ Associated anomalies } & \multicolumn{2}{|l|}{ Group } \\
\hline & & PSARP & ASARP \\
\hline \multirow[t]{3}{*}{ Cardiovascular anomalies } & Ventricular septal defect & 3 & 0 \\
\hline & Atrioseptal defect & 2 & 1 \\
\hline & Patent ductus arteriosus & 3 & $\mathrm{I}$ \\
\hline \multirow[t]{3}{*}{ Neuro-skeletal anomalies } & Lipomeningomyelocele & I & 0 \\
\hline & Spinal vertebrae deformities & 4 & 0 \\
\hline & Radial agenesis & 1 & 0 \\
\hline \multirow[t]{6}{*}{ Urogenital anomalies } & Horseshoe kidneys & I & 0 \\
\hline & Hydronephrosis & I & 0 \\
\hline & Renal agenesis & 6 & 0 \\
\hline & Vesicoureteric reflux & 5 & 0 \\
\hline & Ectopic ureter & 1 & 0 \\
\hline & Vaginal atresia & 2 & 0 \\
\hline \multirow[t]{2}{*}{ Miscellanous } & Absent septum pellucidum with holoprosencephaly & I & 0 \\
\hline & Bilateral leukomalacia & I & 0 \\
\hline
\end{tabular}

Abbreviations: ASARP, anterior sagittal anorectoplasty; PSARP, posterior sagittal anorectoplasty.

Table 2 Complications during the perioperative period

\begin{tabular}{|c|c|c|c|c|}
\hline \multirow{2}{*}{$\begin{array}{l}\text { Complications/ } \\
\text { group }\end{array}$} & \multicolumn{4}{|c|}{ Complications } \\
\hline & $\begin{array}{l}\text { ID } \\
\text { number }\end{array}$ & ASARP & $\begin{array}{l}\text { ID } \\
\text { number }\end{array}$ & PSARP \\
\hline \multirow[t]{3}{*}{ Stoma creation } & & Not performed & 1 & Prolapse, requiring reoperation for refashioning \\
\hline & & & 2 & $\begin{array}{l}\text { Proximal loop of colostomy retracted, treated } \\
\text { conservatively }\end{array}$ \\
\hline & & & 3 & $\begin{array}{l}\text { Bleeding from colostomy + intestinal obstruction } \\
\text { secondary to adhesion + parastomal herniation } \\
\text { treated conservatively }\end{array}$ \\
\hline \multirow[t]{2}{*}{$\begin{array}{l}\text { Definitive } \\
\text { surgery }\end{array}$} & 1 & $\begin{array}{l}\text { Perineal body breakdown, neoanus intact, NS } \\
\text { flushing } 3 \text { hourly, allowed feeding, antibiotic for } \\
\text { I week. Ward stay I week. }\end{array}$ & 1 & $\begin{array}{l}\text { Superficial dehiscence of anterior and posterior } \\
\text { part of wound, about } 1 \mathrm{~cm} \text { each }\end{array}$ \\
\hline & 2 & $\begin{array}{l}\text { Perineal body breakdown, neoanus intact, NS } \\
\text { flushing } 3 \text { hourly, allowed feeding, antibiotic for } \\
\text { I week. Ward stay I week. }\end{array}$ & 2 & $\begin{array}{l}\text { Swelling and pus discharge at neoanus (6 o'clock), } \\
\text { treated with antibiotics }\end{array}$ \\
\hline \multirow[t]{3}{*}{ Stoma closure } & & Not performed & 1 & $\begin{array}{l}\text { Anastomotic leak, noted at day } 8 \text {, requiring } \\
\text { laparotomy and colostomy. Reversal of stoma for } \\
\text { second time done at } 10 \text { months }\end{array}$ \\
\hline & & & 2 & $\begin{array}{l}\text { Had complete wound dehiscence, requiring } \\
\text { reduction of bowel and reclosure of burst wound }\end{array}$ \\
\hline & & & 3 & $\begin{array}{l}\text { Cancellation of operation twice due to URTI and } \\
\text { impacted feces in rectum requiring rectal washout } \\
\text { under GA }\end{array}$ \\
\hline
\end{tabular}

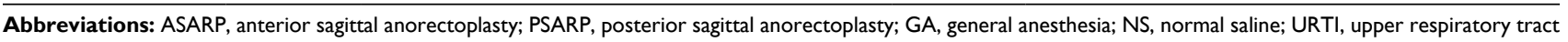
infection.

\section{Complications}

We divided the complications of PSARP according to the surgical stage, that is, loop colostomy (first stage), definitive surgery (second stage), and stoma closure (third stage). Three patients developed complications after the first stage; two patients with a single complication, that is, one developed prolapsed stoma and another had retracted stoma, and the third patient had multiple complications, that is, bleeding, intestinal obstruction requiring laparotomy, and parastomal herniation (Table 2).

Immediately after the definitive surgery, one patient had perianal body breakdown while another had neoanus 
breakdown. Both were treated conservatively with dressing and antibiotics.

After the third stage stoma closure, two patients required major revision surgery due to complications associated to closure. Another patient included in the perioperative complication had the third stage surgery postponed twice due to impacted feces and respiratory infection.

\section{Duration of anal dilatation of PSARP patients}

Majority of PSARP patients (84\%) had to undergo anal dilatation between 1 and 6 months before closure of colostomy (Figure 6).

\section{Duration from formation of stoma to closure of stoma}

The overall interval from creation of stoma to its closure ranged from 4 to 34.2 months. Mean duration taken to complete all three stages of repair was 11.4 months, that is, almost 1 year (Figure 7).

\section{Assessment on bowel habit}

Functional assessment after the age of 2 years

On follow-up, all ASARP patients were above 2 years and were being toilet trained. All except one patient had once a day bowel habit. Only one patient reported straining during defecation. All children had the urge for defecation during the time of assessment.

Out of the 25 patients in the PSARP group, we could only assess 22 patients. They were $>2$ years old and were being toilet trained at the time of study. Their bowel functions were

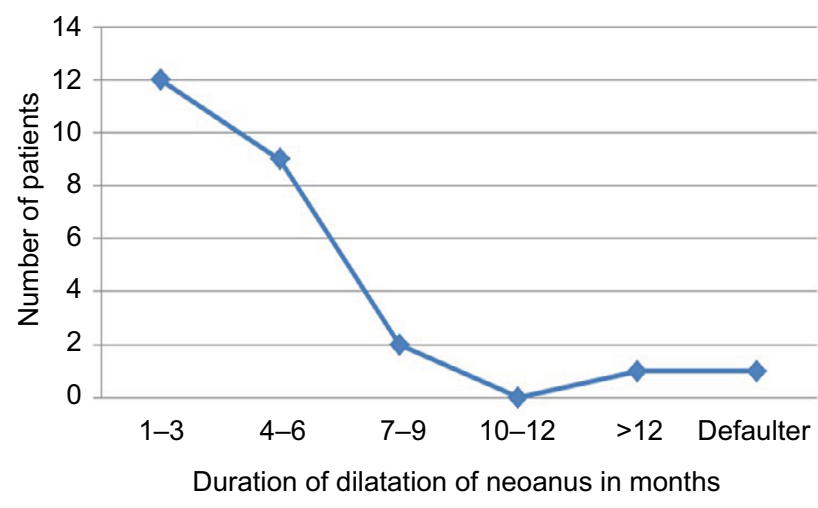

Figure 6 Duration of dilatation of the neoanus among ASARP patients. Abbreviation: ASARP, anterior sagittal anorectoplasty. more variable. Three patients were too young and had no urge for bowel movements during the time of interview.

\section{Parents' satisfaction}

Parents of 15 children in the PSARP group were satisfied with their children's bowel opening while parents of seven children were not. Among the seven children, two had straining, two required manual maneuvers, two had chronic hard stools, and one child had soiling (Figure 8).

\section{Use of laxative}

With regard to the requirement of laxative or stool softeners for the PSARP children, 14 children had their bowel opening regulated by regular diet, five out of 22 children required laxatives regularly, while three other children required laxatives on pro re nata basis. As for the frequency of bowel opening, 10 patients had bowel opening once a day, while the rest had

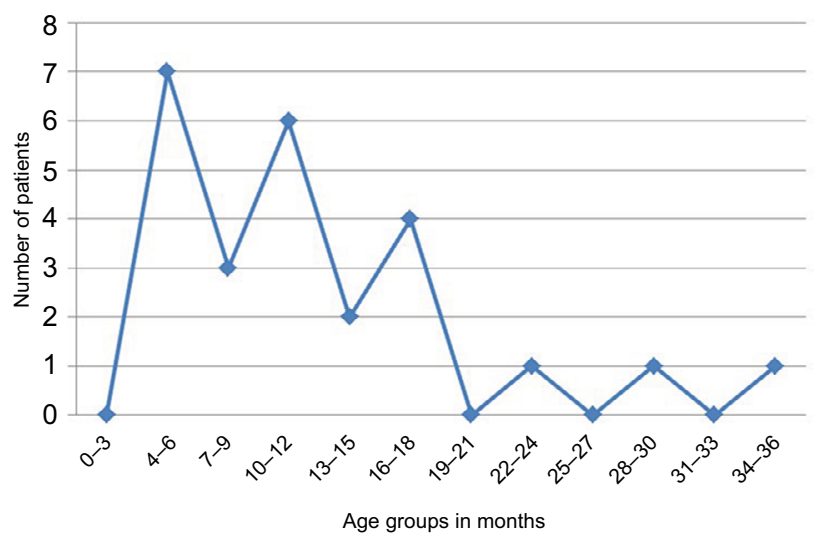

Figure 7 Duration in months from formation of stoma to closure of stoma.

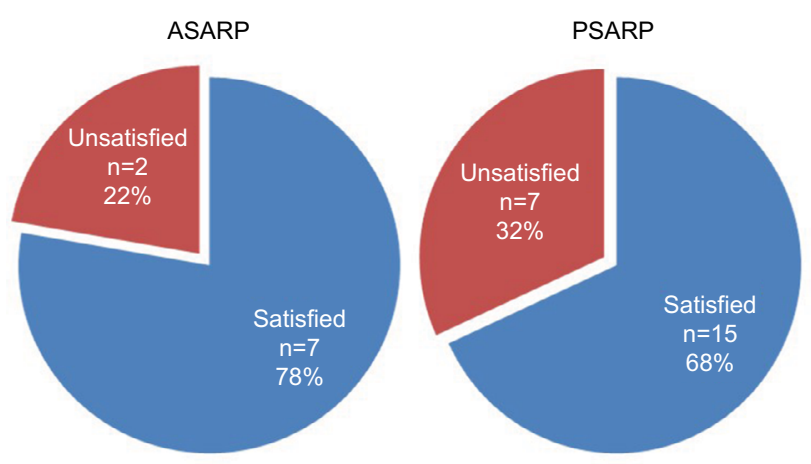

Figure 8 Proportion of parents in ASARP and PSARP who were satisfied with the functional outcome post-surgery.

Abbreviations: ASARP, anterior sagittal anorectoplasty; PSARP, posterior sagittal anorectoplasty. 
a frequency of $\geq 2$ in a day; one child had bowel opening once every 3 days (Figure 9).

\section{Early surgical outcome comparison between ASARP and three-stage PSARP}

There was no statistically significant relationship between the early surgical outcome of ASARP and PSARP, although PSARP had overall poorer results $(P=0.439)$ (Figure 10; Table 3).

\section{Early functional assessment comparison between ASARP and three-stage PSARP}

Overall, there was no statistical significance between the functional outcome of ASARP and PSARP group, except for the assessment frequency $(P=0.032)$ (Table 4$)$.

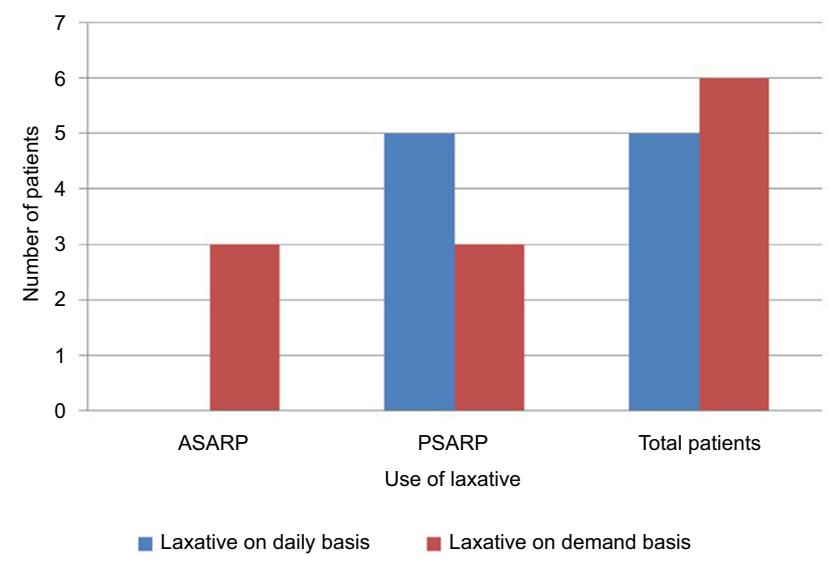

Figure 9 Number of patients requiring laxative in ASARP versus PSARP. Abbreviations: ASARP, anterior sagittal anorectoplasty; PSARP, posterior sagittal anorectoplasty.

\section{Discussion}

In the management of ARAs, restoration of anorectal continuity with optimal sphincter function, early postnatal establishment of the brain-defecation reflex, reduction of physical and psychological stress to the patient and family remain the main objectives. ${ }^{24}$ Based on previous studies, it is shown that primary ASARP is adequate to achieve this aim in the treatment of RVF. ${ }^{24}$ This is because in RVF, the rectal pouch has already transversed the levator ani muscle and ASARP is adequate for mobilization of rectal pouch without cutting the levator ani muscle which is crucial to maintain continence mechanism. We conducted this study to assess the feasibility of this current trend, that is, performing a singlestage ASARP even in neonates. We also did a retrospective historical comparison of early surgical outcomes between

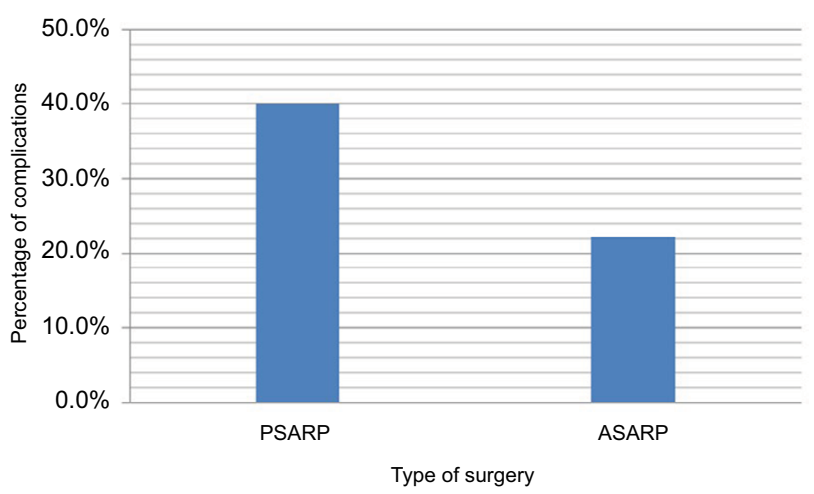

Figure 10 Overall percentage of perioperative complications. Abbreviations: ASARP, anterior sagittal anorectoplasty; PSARP, posterior sagittal anorectoplasty.

Table 3 Calculation of statistical significance of perioperative complications

\begin{tabular}{|c|c|c|c|c|c|c|}
\hline \multirow{2}{*}{\multicolumn{3}{|c|}{ Presence of complications }} & \multicolumn{3}{|l|}{ Group } & \multirow[t]{2}{*}{ Total } \\
\hline & & & PSARP & \multicolumn{2}{|c|}{ ASARP } & \\
\hline \multicolumn{2}{|c|}{ Number of cases without complication } & & 15 & \multicolumn{2}{|l|}{7} & 22 \\
\hline \multicolumn{2}{|c|}{ Number of cases with complication(s) } & & 10 & \multicolumn{2}{|l|}{2} & 12 \\
\hline \multicolumn{2}{|l|}{ Total } & & 25 & \multicolumn{2}{|l|}{9} & 34 \\
\hline Type of test & Value & $d f$ & $\begin{array}{l}\text { Asymp. sig } \\
\text { (2-sided) }\end{array}$ & $\begin{array}{l}\text { Exact sig } \\
\text { (2-sided) }\end{array}$ & $\begin{array}{l}\text { Exact sig } \\
\text { (I-sided) }\end{array}$ & $\begin{array}{l}\text { Point } \\
\text { probability }\end{array}$ \\
\hline Pearson's chi-square & 0.916 & 1 & 0.339 & 0.439 & 0.297 & \\
\hline Continuity correction b & 0.303 & 1 & 0.582 & & & \\
\hline Likelihood ratio & 0.964 & 1 & 0.326 & 0.439 & 0.297 & \\
\hline Fisher's exact test & & & & 0.439 & 0.297 & \\
\hline Linear-by-linear association & 0.889 & 1 & 0.346 & 0.439 & 0.297 & 0.215 \\
\hline Number of valid cases & 34 & & & & & \\
\hline
\end{tabular}

Note: Blank spaces in the table indicate that the value was not available.

Abbreviations: ASARP, anterior sagittal anorectoplasty; PSARP, posterior sagittal anorectoplasty; Asymp, asymptotic; sig, significance. 
Table 4 Calculation of statistical significance of early functional assessment

\begin{tabular}{|c|c|c|c|c|c|}
\hline \multirow{3}{*}{$\begin{array}{l}\text { Bowel habit } \\
\text { and stool } \\
\text { appearance }\end{array}$} & \multicolumn{4}{|c|}{ Function } & \multirow[t]{3}{*}{ Significance } \\
\hline & \multicolumn{2}{|c|}{ ASARP } & \multicolumn{2}{|c|}{ PSARP } & \\
\hline & $\overline{\mathbf{N}}$ & $\overline{\text { Percentage }}$ & $\overline{\mathbf{N}}$ & $\overline{\text { Percentage }}$ & \\
\hline \multicolumn{6}{|l|}{ Color } \\
\hline Mixed & 0 & 0.00 & 1 & 4.55 & 1.000 \\
\hline Normal & 9 & 100.00 & 21 & 95.45 & \\
\hline \multicolumn{6}{|l|}{ Consistency } \\
\hline Hard & 0 & 0.00 & 4 & 18.18 & \\
\hline Mixed & 2 & 45.45 & 10 & 45.45 & 0.176 \\
\hline Soft & 7 & 36.36 & 8 & 36.36 & \\
\hline \multicolumn{6}{|l|}{ Frequency } \\
\hline $\begin{array}{l}\text { More than } 4 \\
\text { times a day }\end{array}$ & I & II.II & 0 & 0.00 & \\
\hline Once a day & 8 & 88.89 & 10 & 45.45 & 0.032 \\
\hline Once every & 0 & 0.00 & 1 & 4.55 & \\
\hline 3 days & & & & & \\
\hline $\begin{array}{l}\text { Three times } \\
\text { a day }\end{array}$ & 0 & 0.00 & 4 & 18.18 & \\
\hline Twice a day & 0 & 0.00 & 7 & 31.82 & \\
\hline \multicolumn{6}{|c|}{ Satisfaction during } \\
\hline \multicolumn{6}{|l|}{ defecation } \\
\hline Satisfied & 7 & 77.77 & 15 & 68.18 & 0.689 \\
\hline Unsatisfied & 2 & 22.22 & 7 & 31.82 & \\
\hline \multicolumn{6}{|c|}{$\begin{array}{l}\text { Laxative required } \\
\text { daily }\end{array}$} \\
\hline No & 9 & 100.00 & 17 & 77.27 & 0.286 \\
\hline Yes & 0 & 0.00 & 5 & 22.73 & \\
\hline \multirow{2}{*}{\multicolumn{6}{|c|}{$\begin{array}{l}\text { Laxative on } \\
\text { demand basis }\end{array}$}} \\
\hline & & & & & \\
\hline No & 6 & 63.64 & 19 & 86.36 & 0.320 \\
\hline Yes & 3 & 13.64 & 3 & 13.64 & \\
\hline \multirow{2}{*}{\multicolumn{6}{|c|}{$\begin{array}{l}\text { Urge for } \\
\text { defecation }\end{array}$}} \\
\hline & & & & & \\
\hline No & 0 & 0.00 & 5 & 22.73 & 0.286 \\
\hline Yes & 9 & 100.00 & 17 & 77.27 & \\
\hline
\end{tabular}

Abbreviations: ASARP, anterior sagittal anorectoplasty; PSARP, posterior sagittal anorectoplasty.

primary neonatal ASARP and three-stage PSARP. This comparison study is an extension to the recently published experience of ASARP without anal dilatation in neonates by Dayang et al. ${ }^{44}$ To date, there has been no prospective or retrospective study to assess long- and short-term outcome of primary neonatal ASARP with conventional three-stage PSARP for RVF in the literature.

\section{Early surgical outcome}

In this study, we have shown that primary ASARP without anal dilatation can be performed in neonates with minimal complications. Immediately postoperatively, their oral intake is not withheld beyond the time required for anesthetic purposes. Though not on dilatation, EUA done
1 month postoperatively showed only slight reduction in neoanus size which is still appropriate for age. Postoperative wound infection was reported twice in both ASARP and PSARP groups and all were treated conservatively without sequelae. The infection rate for ASARP is $22 \%$ in this series, higher than previous series..$^{24,37,45}$ However, the reported wound breakdown in the ASARP group involving the perineal body is only for the first two cases, probably reflecting the learning curve of the surgeon during the initial stages. They were managed conservatively with therapeutic antibiotics for 1 week and 3 hourly with normal saline flushing for a week. Factors responsible for the improvement of results include better surgical technique and dissection with growing experience, less tissue trauma, adequate rectal mobilization, and absence of hemorrhage leading to hematoma. There is no complete wound dehiscence in both groups. In this historical comparison, there was no statistical significance in the comparison of early surgical outcome between two groups. Based on this outcome, we can conclude that ASARP is as good as PSARP in the management of RVF if not superior.

\section{Need for protective colostomy}

Traditionally, protective colostomy is advocated in the repair of RVF. The reason for this is to prevent major complications such as anastomotic leak or wound dehiscence from occurring in the immediate postoperative period. In the event of a major complication occurring, protective colostomy is meant to prevent three additional operations, that is, colostomy in the immediate postoperative period, followed by a redo repair, and finally a colostomy closure. A redo surgery is known to have poorer functional outcome. Secondly, the dissection required in RVF is almost as extensive as for higher lesions thereby justifying a protective colostomy. ${ }^{46,47}$

However, based on this study, we observed that colostomy could result in significant morbidity if not constructed meticulously. Through ASARP, total correction can be achieved in one instead of three stages. There was no major wound sepsis among the primary ASARP patients in this study. The need for colostomy was eliminated because the mobilization of rectum is better visualized and division of the sphincteric muscle complex is limited to the anterior aspect, thus reducing tissue manipulation and risk of infection. We could conclude that another advantage of ASARP was avoidance of the proximal pelvic colostomy (required in the classical PSARP technique) without the 
risk of wound sepsis. Besides that, single-stage ASARP will also avoid repeated hospitalizations, which could translate to reduction of total cost of treatment and avoidance of major complications associated with colostomy formation and closure.

\section{Should parents perform daily anal dilatation?}

In a larger study by Wakhlu et al involving 49 patients, anal stenosis was reported in $1.44 \%$ of cases of ASARP. ${ }^{18}$ In our study, none of the patients who underwent ASARP developed stenosis despite not being on dilatation program. The threestage PSARP group did not report any case of stenosis too. However, in that group, patients were subjected to a long period of daily anal dilatation. Our study showed no significant differences between the two approaches with regard to stricture development. Nevertheless, we could conclude that by performing ASARP, anal dilatation was avoided. This will certainly ease postoperative management for the parents or caretaker. It was certainly child-friendly, not having to dilate the baby's anus, and yet achieved similar results to the threestage PSARP.

\section{Bowel function outcome}

Bowel control implies the ability to detect and retain flatus and stool until the appropriate time for evacuation. In children with ARA, bowel function is affected due to multiple factors including complex interplay among sphincter function, anorectal sensation, and colonic motility ${ }^{48}$ Functional assessment was carried out for 22 cases from the PSARP group and nine from the ASARP group who passed the 24 months postoperative period and who were compliant to the follow-up visits.

Normal bowel habits without the need for laxative were reported in $67 \%$ of cases in the ASARP group when followed beyond the age of 2 years. Only one patient had straining during defecation suggestive of stenosis or stricture. However, the digital examination during follow-up was normal. This result is almost similar to the result reported by Wakhlu et al. ${ }^{23}$ In comparison, for the PSARP patients, a normal bowel habit is achieved without the need for laxative in only $45 \%$ of the patients. Fecal impaction is not reported in this study although ASARP is linked to this peculiar problem due to prominent posterior anal ledge; this condition could be detected via rectal examination. There was only one case of soiling from the PSARP group. This unfortunate child did not have any surgical complications earlier. Soiling is normally attributed to children who develop complications post-surgery requiring revision surgery.

There was only one parameter with statistical significance between the two groups, which was the ASARP group had more normal frequency of bowel opening compared to the PSARP group $(P=0.032)$. Although encouraging, a better conclusion on functional bowel assessment would require bigger numbers of samples from both groups and longer follow-up.

\section{Conclusion}

To our knowledge, this is the first retrospective study designed to compare early surgical and functional outcomes of primary neonatal ASARP without covering stoma and postoperative anal dilatation to three-stage PSARP in the treatment of girls with RVF. The results of this study show that primary neonatal ASARP is an acceptable and feasible technique for the treatment of RVF. Overall early surgical outcomes in ASARP were superior to PSARP. Excellent continence was achieved in most cases following ASARP technique even without anal dilatation. The short-term functional outcome assessed after 2 years shows that ASARP produced consistent good results. However, there was no statistical significance between the two techniques.

\section{Disclosure}

The authors report no conflicts of interest in this work.

\section{References}

1. Okada A, Shinkichi K, Imura K, et al. Anterior sagittal anorectoplasty for rectovestibular and anovestibular fistula. J Pediatr Surg. 1992;27:85-88.

2. Rintala RJ. Anorectal malformations management and outcome. Semin Fetal Neonatol Med. 1996;1:219-230.

3. Pakarinen MP, Rintala RJ. Management and outcome of low anorectal malformations. Pediatr Surg Int. 2010;26:1057-1063.

4. Peña A, Devries P. Posterior sagittal anorectoplasty: important technical considerations and new applications. J Pediatr Surg. 1982;17:796-811.

5. de Vries PA, Pena A. Posterior sagittal anorectoplasty. J Pediatr Surg. 1982;17:638-643.

6. Günşar C, Genc A, Şencan A, Dağlar Z, Alparslan O, Mir E. Association and rectovestibular fistula: case report of a patient treated with one-stage posterior sagittal anorectoplasty and sigmoid loop vaginoplasty. J Pediat Surg. 2003;38(2):262-264.

7. Stephens FD, Smith ED. Operative management of rectal deformities. In: Anorectal Malformations in Children. Chicago, IL: Year Book Medical Publishers; 1971:212-257.

8. Murphy F, Puri P, Hutson JM, Holschneider AM. Incidence and Frequency of Different Types and Classification of Anorectal Malformations. Berlin, Heidelberg: Springer Verlag; 2006:163-184.

9. Louw JH. Congenital abnormalities of the rectum and the anus. Curr Probl Surg. 1965;31:1-64.

10. Spouge D, Baird PA. Imperforate anus in 700,000 consecutive liveborn infants. Am J Med Genet Suppl. 1986;2:151-161.

11. Hashmi MA, Hashmi S. Anorectal malformations in female children - 10 years experience. J R Coll Surg Edinb. 2000;45:153-158. 
12. Chowdhary SK, Chalapathi G, Narasimhan KL, et al. An audit of neonatal colostomy for high anorectal malformation: the developing world perspective. Pediatr Surg Int. 2004;20:111-113.

13. Yang JH, Kim YJ, Chung JH, et al. A multi-center study for birth defect monitoring systems in Korea. J Korean Med Sci. 2004;19:509-513.

14. Borman B. Annual report with data for 2000, International Clearinghouse for Birth Defects Monitoring Systems. Roma, Italy: International Centre for Birth Defects; 2000.

15. Tong MC. Anorectal anomalies: a review of 49 cases. Ann Acad Med Singapore. 1981;10:479-484.

16. Chatterjee SK. Lesions in the wingspread list management in the neonatal period. In: Chatterjee SK, editor. Anorectal Malformations: A Surgeon's Experience. Chap 8. New Delhi, India: Oxford University Press; 1991:48-64.

17. Smith ED. The bath water needs changing, but don't throw out the baby: an overview of anorectal anomalies. J Pediatr Surg. 1987;22:335-348.

18. Wakhlu A, Pandey A, Prasad A, et al. Anterior sagittal anorectoplasty for anorectal malformations and perineal trauma in the female child. J Pediatr Surg. 1996;31(9):1236-1240.

19. Tsuji H, Okada A, Nakai H, Azuma T, Yagi M, Kubota A. Follow-up studies of anorectal malformations after posterior sagittal anorectoplasty. J Pediatr Surg. 2002;37:1529-1533.

20. Rintala $R$, Lindahl $H$. Is normal bowel function possible after repair of intermediate and high anorectal malformations. J Pediatr Surg. 1995;30:491-494.

21. Javid PJ, Barnhart DC, Hirschl RB, Coran AG, Harmon CM. Immediate and long term results of surgical management of low imperforate anus in girls. J Pediatr Surg. 1998;33:198-203.

22. Waheeb SM. The anterior sagittal anorectoplasty technique (ASARP) for treatment of recto-vestibular fistulae and vestibular anus in children and neonates. Ann Pediatr Surg. 2005;1:54-58.

23. Wakhlu A, Kureel SN, Tandon RK, Wakhlu AK. Long-term results of anterior sagittal anorectoplasty for the treatment of vestibular fistula. J Pediatr Surg. 2009;44:1913-1919.

24. Shehata SM. Prospective long-term functional and cosmetic results of ASARP versus PSARP in treatment of intermediate anorectal malformations in girls. Pediatr Surg Int. 2009;25:863-888.

25. Kulshrestha S, Kulshrestha M, Singh B, Sarkar B, Chandra M, Gangopadhyay AN. Anterior sagittal anorectoplasty for anovestibular fistula. Pediatr Surg Int. 2007;23:1191-1197.

26. Rangel SJ, de Blaauw I. Advances in pediatric colorectal surgical techniques. Semin Pediatr Surg. 2010;19(2):86-95.

27. Adeniran JO, Abdur-Rahman L. One-stage correction of imperforate anus and rectovestibular fistula in girls: preliminary results. $J$ Pediatr Surg. 2002;37(6):E16.

28. Adeniran J. One-stage correction of intermediate imperforate anus in males. Pediatr Surg Int. 2005;21:88-90.

29. Albanese C, Jennings RW, Lopoo JB, Bratton BJ, Harrison MR. Onestage correction of high imperforate anus in the male neonate. J Pediatr Surg. 1999;34:834-836.
30. Patwardhan N, Kiety EM, Drake DP, Spitz L, Pierro A. Colostomy for anorectal anomalies: high incidence of complications. J Pediatr Surg. 2001;36:795-798

31. Pena A, Migotto-Krieger M, Levitt MA. Colostomy in anorectal malformations: a procedure with serious but preventable complications. J Pediatr Surg. 2006;41:748-756.

32. Mollitt DL, Malangoni MA, Ballantine TV, Grosfeld JL. Colostomy complications in children. An analysis of 146 cases. Arch Surg. 1980;115:455-458.

33. Moore TC. Advantages of performing the sagittal anoplasty operation for imperforate anus at birth. J Pediatr Surg. 1990;25:276-277.

34. Chaudhary RP, Thapa B, Thana S, Singh PB. Single stage anterior sagittal anorectoplasty (ASARP) for anorectal malformations with vestibular fistula and perineal ectopic anus in females: a new approach. $J$ Nepal Paediatr Soc. 2010;30:37-43.

35. Kumar M, Kandpal DK, Sharma SB, Agrawal LD, Jhamariya VN. Single-stage repair of vestibular and perineal fistulae without colostomy. J Pediatr Surg. 2008;43:1848-1852.

36. Rintala RJ. Congenital anorectal malformations: anything new? J Pediatr Gastroenterol Nutr. 2009;48(Suppl 2):S79-S82.

37. Aziz MA, Banu T, Prasad R, Khan AR. Primary anterior sagittal anorectoplasty for rectovestibular fistula. Asian J Surg. 2006;29:22-24.

38. Freeman NV, Burge DM, Soar JS, Sedgwick EM. Anal evoked potentials. Z Kinderchir. 1980;31:22-30.

39. Freeman NV, Bulut M. High anorectal anomalies treated by early (neonatal) operation. J Pediatr Surg. 1986;21(3):218-220.

40. Sigalet DL, Laberge JM, Adolph VR, Guttman FM. The anterior sagittal approach for high imperforate anus: a simplification of the Mollard approach. J Pediatr Surg. 1996;31:625-629.

41. Temple SJ, Shawyer A, Langer JC. Is daily dilatation by parents necessary after surgery for Hirschsprung disease and anorectal malformations? J Pediatr Surg. 2012;47:209-212.

42. Holschneider AM, Freeman NV. Anatomy and function of the normal rectum and anus. Birth Defects Orig Artic Ser. 1988;24:125-154.

43. Nour S, Beck J, Stringer MD. Colostomy complications in infants and children. Ann R Coll Surg Engl. 1996;78:526-530.

44. Aziz DA, Marjmin O, Sehat SI, Mohd Nor M. Early experience: anterior sagittal anorectoplasty (ASARP) without anal dilatation in neonates with rectovestibular fistula. ANZ J Surg. 2012;82(Suppl 1):114-125.

45. Zamir N, Mirza FM, Akhtar J, Ahmed S. Anterior sagittal approach for anorectal malformations in female children: early results. $J$ Coll Physicians Surg Pak. 2008;18:763-767.

46. Peña A. Atlas of Management of Anorectal Malformations. New York: Springer; 1997.

47. Heinen FL. The surgical treatment of low anal defects and vestibular fistulas. Semin Pediatr Surg. 1997;6(4):204-216.

48. Levitt M, Peña A. Update on pediatric faecal incontinence. Eur J Pediatr Surg. 2009;19:1-9.
Open Access Surgery

\section{Publish your work in this journal}

Open Access Surgery is an international, peer-reviewed, open access journal that focuses on all aspects of surgical procedures and interventions Patient care around the peri-operative period and patient outcomes post surgery are key topics for the journal. All grades of surgery from minor cosmetic interventions to major surgical procedures are covered. Novel techniques and the

\section{Dovepress}

utilization of new instruments and materials, including implants and prostheses that optimize outcomes constitute major areas of interest. The manuscrip management system is completely online and includes a very quick and fair peer-review system, which is all easy to use. Visit http://www.dovepress.com testimonials.php to read real quotes from published authors. 